mothers. Paternal transmission also seems to be associated with expansion of the repeat, but whether or not this applies to maternal transmission is unclear. ${ }^{4}$ This is interesting as similar findings have been reported in myotonic dystrophy. In this condition the gene also contains an unstable trinucleotide repeat, although the severe phenotype is transmitted by affected females. ${ }^{8}$ These observations provide a molecular substrate for the previously controversial phenomenon of anticipation (the apparent tendency for autosomal dominant diseases to be more severe in younger than older generations of a family.)

The possibility of fresh mutation in Huntington's disease has, until now, been difficult to prove. Two such events were identified in patients with the features of Huntington's disease but who had unaffected parents. ${ }^{2}$ It seems that the gene containing an expanded CAG repeat in these patients is derived from a parental one in which the repeat is at the upper limit of the normal range, indicating a premutational state.

How the expanded repeat, assuming it is translated, causes cellular dysfunction in Huntington's disease and why this applies to some parts of the brain but not others are just two unexplained issues. What is tantalising is that not only Huntington's disease and myotonic dystrophy but also three other neurological disorders (X linked bulbospinal neuronopathy and the fragile $\mathrm{X}$ syndrome, and one type of dominant ataxia) are associated with unstable trinucleotide repeats. ${ }^{10}$ Other genes of known and unknown function containing such repeat sequences are expressed in the human brain. ${ }^{112}$ There must be other neurological diseases that are caused by this curious type of mutation-a hypothesis that has not escaped the attention of the neurogenetic community at large.

A E HARDING

Neurogenetics Section,

Professor of clinical neurology

Department of Clinical Neurology,

Institute of Neurology,

London, WC1N 3BG

1 Gusella JF, Wexler NS, Conneally PM, Naylor SL, Anderson MA, Tanzi RE, et al. A polymorphic DNA marker genetically linked to Huntington's disease. Nature 1983;306:234-8.

2 Huntington's Disease Collaborative Research Group. A novel gene containing a trinucleotide repeat that is expanded and unstable on Huntington's disease chromosomes. Cell 1993;72: 971-83.

3 MacDonald ME, Haines $\mathrm{J}$, Zimmer M, Cheng SV, Youngman S, Whaley WL, et al. Recombination events suggest potential sites for the Huntington's disease gene. Neuron 1989;3: $183-90$.

4 Snell R, MacMillan JC, Cheadle JP, Fenton I, Lazarou L, Davies P, et al. Expansion of a specific trinucleotide reeat sequence in Huntington's disease. The molecular basis of phenotypic variation. Nature Genetics (in press).

5 Valdes JM, Tagle DA, Elmer LW, Collins FS. A simple non-radioactive method for diagnosis of Huntington's disease. Human Molecular Genetics 1993;2:633-4.

6 Goldberg YP, Andrew SE, Clarke LA, Hayden MR. A PCR method for accurate assessment of trinucleotide repeat expansion in Huntington's disease. Human Molecular Genetics 1993;2:635-6. Riess O, Noerremoelle A, Soerensen SA, Eppien JT. Improved PCR conditions for the stretch of (CAG) $)_{n}$ repeats causing Huntington's disease. Human Molecular Genetics 1993;2:637-8.

8 Harley HG, Rundle SA, Reardon W, Myring J, Crow S, Brook JD, et al. Unstable DNA sequences in myotonic dystrophy. Lancet 1992;339:1125-8.

9 Suthers GK, Huson SM, Davies KE. Instability versus predictability: the molecular diagnosis of myotonic dystrophy. $\mathcal{F}$ Med Genet 1992;29:761-5.

10 Orr HT, Chung M, Banfi S, Kwiatkowski TJ, Servadio A, Beaudet AL, et al. Expansion of an unstable trinucleotide CAG repeat in spinocerebellar ataxia type 1. Nature Genetics 1993;4:221-6.

1 Riggins GJ, Wilcox AS, Polymeropoulos MH, Hopkins JA, Stevens TJ, Robinson M, et al. Human genes containing polymorphic trinucleotide repeats. Nature Genetics 1992;2:186-91.

$12 \mathrm{Li} \mathrm{S}-\mathrm{H}$, McInnis MG, Margolis RL, Antonarakis SE, Ross CA. Novel triplet repeat containing genes in human brain: cloning, expression, and length polymorphisms. Genomics 1993;3: 572-9.

\title{
Clinical consequences of isolating the gene for Huntington's disease
}

\author{
An accurate test brings a set of ethical problems
}

After 10 years of intensive international research the isolation of the gene for Huntington's disease is already having major scientific and clinical consequences. ${ }^{1}$ The most immediate clinical consequences are genetic and arise from the specificity of the genetic change in relation to Huntington's disease as well as from the fact that almost all families so far studied show the same mutational basis. ${ }^{2}$ A single molecular test on a sample of blood or other tissue now seems likely to predict or diagnose Huntington's disease with a high degree of accuracy. All clinicians and scientists concerned with patients and families affected by Huntington's disease need to recognise the implications of this advance.

Linked DNA markers have been available for presymptomatic testing for several years, ${ }^{34}$ with over 1500 such tests completed worldwide..$^{5-8}$ But the need to test many family members, together with inaccuracy from possible recombination, has made testing difficult for most people and impossible for many. Mutation analysis now allows a test that should be accurate and specific, though both factors will need validating in larger, independent series. Moreover, privacy for the applicant will be enhanced because samples from many relatives are no longer needed (though confirmation of the mutation in at least one affected member will remain important). In the laboratơry testing will be simpler, quicker, and possibly cheaper, though the method is technically demanding and will benefit from modification before being suitable for service use. ${ }^{9}$

Against these undoubted advantages must be weighed some potentially serious problems. The most serious is the possibility of testing without giving information, counselling, and support-especially worrying when economic pressure is being exerted to reduce health service costs and when some British laboratory services are being contracted out. Fortunately, patterns of practice have been established ${ }^{10}$; testing without counselling is generally agreed to be unethical and could have serious legal implications if problems were to arise. In Britain all centres performing presymptomatic testing for Huntington's disease have adopted a common protocol for counselling ${ }^{11}$ and have formed a consortium to monitor testing and audit its practice. ${ }^{12}$ This should form an important safeguard as well as providing a valuable example for genetic testing in other disorders.

Even with the best clinical practice other dilemmas may arise. Testing is sometimes sought by those at $25 \%$ prior risk, who have had an affected grandparent but whose parent is well though still at considerable risk. Testing in response to such a request might disclose that the parent of the person tested carried the gene for Huntington's disease and would thus develop the disorder, even though that person, unlike his or her offspring, did not wish to be tested. It remains to be seen how such potential conflicts of interest will be resolved.

The identification of a specific mutation for Huntington's disease will for the first time give a diagnostic test for the disorder, which can be used to confirm apparently isolated cases and in situations of clinical uncertainty. Such testing is unlikely to alter greatly the range of clinical phenotype resulting from the disease, as has happened with prion dementias, ${ }^{13}$ but it will represent a further extension of molecular genetics into neurological practice. When such testing is carried out in people not known to have a pedigree of 
Huntington's disease great care will be needed to ensure that the test is accompanied by full information on the genetic implications.

An even more difficult question is whether testing should be undertaken diagnostically in a person known to be at risk who has minor or apparently unrelated symptoms. The mutation for Huntington's disease might not be the cause of the clinical problem, and such testing could in effect be prediction rather than diagnosis.

The unstable nature of the Huntington's disease trinucleotide repeat mutation, closely comparable to that responsible for myotonic dystrophy, ${ }^{14}$ makes likely some correlation between the degree of enlargement of the sequence and the age at onset of the disorder. Indeed, this has now been confirmed, ${ }^{2}$ but the range of variation for any given result seems likely to be too great to be clinically useful for individual patients.

A final problem is the possibility of stigmatisation in employment, insurance, and personal relationships. This is not new. It has already been encountered by those undergoing presymptomatic testing by linked markers and to some degree by most people with a family history of Huntington's disease. Mutation testing will, however, increase the potential for such problems and is yet another incentive for society to monitor and regulate the use of genetic testing generally if it is not to become abused.

The identification of the gene for Huntington's disease and the use of mutation testing in clinical practice will provide major challenges and problems for both families and professionals. It would be wrong, however, to overemphasise the negative aspects. For many people, testing will lift the shadow under which they have lived for many years, while the prospect of understanding the pathogenesis of the disease brings the possibility of treatment a step nearer. When a treatment is developed many of the present dilemmas of presymptomatic testing will disappear and true prevention of Huntington's disease may at last become a reality.

\section{PETER S HARPER}

Professor

Institute of Medical Genetics,

University of Wales College of Medicine,

Cardiff CF4 4XN

1 Huntington's Disease Collaborative Research Group. A novel gene containing a trinucleotide repeat that is expanded and unstable on Huntington's disease chromosomes. Cell 1993;72. repeat that

2 Snell RG, MacMillan JC, Cheadle JP, Fenton I, Lazarou L, Davies P, et al. Expansion of a specific trinucleotide repeat sequence in Huntington's disease. The molecular basis of phenotypic variation. Nature Genetics (in press).

3 Meissen GJ, Myers RH, Mastromauro CA, Koroshetz WJ, Klinger KW, Farrer LA, et al. Predictive testing for Huntington's disease with use of a linked DNA marker. $N$ Engl $f$ Med 1988;318:535-42.

4 Hayden MR, Robbins C, Allard D, Haines J, Fox S, Wasmuth J, et al. Improved predictive testing for Huntington's disease by using three linked DNA markers. Am $\mathcal{G}$ Hum Genet 1988;43:689-94.

5 World Federation of Neurology Research Group on Huntington's Disease. Presymptomatic testing for Huntington's disease. A world-wide survey. $\mathcal{f}$ Med Genet (in press).

6 Craufurd D, Dodge A, Kerzin-Storrar L, Harris R. Uptake of presymptomatic predictive testing for Huntington's disease. Lancet 1989;ii:603-5.

7 Brock DH, Mennie M, Curtis A, Millan FA, Barron L, Raeburn JA, et al. Predictive testing for Huntington's disease with linked DNA markers. Lancet 1989;i:463-6.

8 Tyler A, Morris M, Lazarou L, Meredith L, Myring J, Harper PS. Presymptomatic testing for Huntington's disease in Wales 1987-1990. Br $\mathcal{F}$ Psychiatry 1992;161:481-8.

9 Warner JP, Barron LH, Brock DJH. A new polymerase chain reaction (PCR) assay for the trinucleotide repeat that is unstable and expanded on Huntington's disease chromosomes. Molecular and Cellular Probes 1993;7:235-9.

10 World Federation of Neurology Research Group on Huntington's Disease. Ethical issues policy statement on Huntington's disease molecular genetics predictive test. $f$ Med Genet 1990;27:34-8.

11 Craufurd D, Tyler A, on behalf of the UK Huntington's Prediction Consortium. Predictive testing for Huntington's disease: protocol of the UK Huntington's prediction consortium. $\mathfrak{f}$ Med Genet 1992;29:915-8.

12 Tyler A, Ball D, Craufurd D. Presymptomatic testing for Huntington's disease in the United Kingdom. $B M 7$ 1992;304:1593-6.

13 Collinge J, Palmer MS, Dryden AJ. Genetic predisposition to iatrogenic Creutzfeldt-Jakob disease. Lancet 1991;337:1441-2

14 Harley HG, Rundle SA, Reardon W, Myring J, Crow S, Brook JD, et al. Unstable DNA sequence in myotonic dystrophy. Lancet 1992;339:1125-8.

\title{
How should another Camelford be managed?
}

\author{
By better planning and more openness
}

Five years ago 20000 people in the Camelford area of Cornwall were exposed to high concentrations of aluminium in their drinking water after 20 tonnes of aluminium sulphate was mistakenly put into the water at Lowermoor Water Treatment Works. They were exposed for a few days, as the fault was detected and corrective measures were started within six hours. The water tasted unpleasant because of its acidity and aluminium content; it also contained abnormal amounts of copper and zinc dissolved from pipes. The initial toxicological assessment was that the limited exposure would not cause acute or chronic disease.

Two years later, however, 400 people had illnesses that they attributed to the incident. There is objective evidence from a few patients that skeletal and neuropsychological effects were present for 12 to 18 months. ${ }^{1}$ An expert review, chaired by Professor Dame Barbara Clayton, could not find biochemical explanations for the reported illnesses but interpreted the symptoms as "real mental and physical suffering" resulting from the anxieties created by the incident. ${ }^{23}$ The anxiety and the disputes about the effects on health would have been less if the public had been better informed about the incident from the outset. Those who may have to manage similar incidents should prepare their plans for high quality epidemiological assessment and public relations.

The plans should accommodate a variety of unpredictable incidents. Contamination may be by chemicals, radiation, or micro-organisms, and water is only one of the ways by which pollution reaches human populations. A difference exists between acute incidents and persistent contamination, although this distinction is often confused by the public, who suspect that the acute incident is the tip of an iceberg.

Acute chemical pollution of drinking water can arise from mistakes made in treatment or from industrial or agricultural chemicals reaching water sources after accidents, fires, or incorrect disposal of waste. Normally the contamination is detected and controlled by the National Rivers Authority and the water companies, and the public is not at risk. Small problems are surprisingly common: 23000 incidents occurred in England and Wales in 1988, on a rising trend. ${ }^{4}$ Incidents on the scale of Camelford are rare. They require special handling because of the needs for alternative water supplies to many homes, public information, and a thorough assessment of the risks to health. These measures cannot be left for the water industry to manage itself.

The participation of multiple agencies, both local and national, requires careful organisation. We cannot assume that the organisation is in place for chemical incidents. ${ }^{5}$ Collaboration has been hindered by the repeated reorganisation of the public health services, the water industry, and central government departments. It is essential that all the agencies are informed immediately when pollution is detected, but there will be doubt in the early stages that the 